\title{
PENGARUH TERAPI INTEGRASI SENSORI TERHADAP TONUS ANAK DENGAN SENSORY INTEGRATION DISORDER (SID) BERDASARKAN SKOR CLINICAL OBSERVATION OF NEUROMOTOR PERFORMANCE (CONP) DI MITRA ANANDA SURAKARTA
}

\author{
Erna Ariyanti Kurnianingsih \\ Kementerian Kesehatan Politeknik Kesehatan Surakarta Jurusan Okupasi Terapi
}

\begin{abstract}
Sensory Integration Therapy-Muscle Tonus-Clinical Observation Of Neuromotor Performance. Special need children such as down syndrome, autism and intellectual disability suffered from Sensory Integration Disorder (SID) will have an impact on the weakness of postural muscle tone. Muscle tone measurement of children with SID is different from other children without SID. Clinical observation of neuromotor performance (CONP) is used as of one of criteria of muscle muscle tone in children with SID. The study aimed at finding theeffect of sensory integration therapy towards muscle tone based on Score of Clinical Observation of Neuromotor Performance (CONP) at Mitra Ananda Surakarta. The study was designed as quasi experiment one group pretest posttest design. population of this study is client with SID at Mitra Ananda Surakarta, by total sampling there are a number of 12 samples. Paired t-test is applied for analizing data with SPSS version 17.0. Paired t-test portrayed p-value > 0.05 it means that there are no significant difference in muscle tone, before and after treatment. Sensory integration therapy doesn't affect muscle tone for shildren with SID Based on Score of Clinical Observation of Neuromotor Performance (CONP) at Mitra Ananda Surakarta
\end{abstract}

Keywords: Sensory Integration Therapy-Muscle Tonus-Clinical Observation Of Neuromotor Performance

\begin{abstract}
Abstrak : Terapi Integrasi Sensori- Tonus- Clinical Observation Of Neuromotor Performance. Gangguan integrasi sensori atau Sensory Integration Disorder (SID) yang dialami anak berkebutuhan khusus seperti down syndrome, autism dan intellectual disability akan berdampak pada kelemahan tonus otot postural. Pengukuran tonus otot pada anak dengan gangguan integrasi sensori tidak sama dengan pengukuran tonus otot pada umumnya. Salah satu cara mengetahui kondisi tonus otot anak dengan gangguan integrasi sensori adalah dengan pemeriksaan clinical observation of neuromotor performance (CONP). Tujuan penelitian ini adalah mengetahui pengaruh terapi integrasi sensori terhadap tonus anak dengan Sensory Integration Disorder berdasarkan Skor Clinical Observation of Neuromotor Performance di Mitra Ananda Surakarta. Desain penelitian dengan rancangan quasi eksperimental one group pretest posttest design. Populasi penelitian adalah klien di Mira Ananda Surakarta. dengan menggunakan totally sampling diperoleh 12 sampel.Analisis data dengan uji paired t-test, dengan program SPSS Versi 17.0. Hasil uji paired t-test meunjukkan nilai $p$-value $>0.05$ yang artinya tidak ada perbedaan yang signifikan tonus otot sebelum dan setelah perlakuan.
\end{abstract}


Terapi integrasi sensori tidak berpengaruh terhadap tonus anak dengan Sensory Integration Disorder berdasarkan skor clinical observation of neuromotor performance

\section{Kata Kunci : Terapi Integrasi Sensori- Tonus- Clinical Observation Of Neuromotor Performance}

\section{PENDAHULUAN}

Gangguan integrasi sensori atau Sensory Integration Disorder (SID) yang dialami anak berkebutuhan khusus seperti down syndrome, autism dan intellectual disability akan berdampak pada kelemahan tonus otot postural. Selama ini perhatian terapis pada anak dengan SID belum sampai pada kondisi tonus otot postural. Sehingga terapi yang sudah didesain terapis belum dapat mencapai hasil yang maksimal. Kondisi ini menyebabkan mereka kesulitan melakukan berbagai aktifitas motorik dan akademik. Tonus otot ini sangat berperan dalam menjaga tubuh pada posisi atau postur tertentu.Perubahan tonus otot mampu membuat individu bergerak. Apabila individu atau anak mempunyai tonus otot rendah maka dia akan lemah dan memerlukan tenaga yang ekstra untuk melakukan aktivitas. Akibat kelemahan tonus otot ini, anak kesulitan mempertahankan postur tubuh yang baik saat duduk atau berdiri dan lebih mudah lelah.

Pengukuran tonus otot pada anak dengan gangguan integrasi sensori tidak sama dengan pengukuran tonus otot pada umumnya. Salah satu cara mengetahui kondisi tonus otot anak dengan gangguan integrasi sensori adalah dengan pemeriksaan clinical observation of neuromotor performance (CONP). Pemeriksaan postur dalam semua pemeriksaan yang berhubungan dengan integrasi sensori dilakukan melalui observasi tentang ketidakmampuan melakukan atau mempertahankan postur prone extention, kesulitan memfleksikan leher saat berada pada posisi supine flexion, rendahnya tonus otot ekstensor ,stabilitas persendian bagian proksimal jelek, dan kesulitan dalam equilibrium (Bundy, 2002).

Dalam melakukan kegiatan seharihari individu harus mampu memfungsikan seluruh otot karena tulang, tendon, dan ligamen dapat bekerja karena adanya aktivitas otot yang melekat pada mereka.Otot-otot tersebut mempunyai kemampuan untuk memanjang dan berkontraksi secara normal. Hal ini membuat individu mampu menggerakkan anggota gerak, telentang, duduk, berdiri dan bahkan berlari (Schoeman, 2012). Gerakan yang dilakukan setiap hari secara berulang-ulang membantu tubuh untuk mengubah gerakan tidak terkontrol menjadi gerakan yang disadari dan terkontrol sebagai reaksi postural yang komplek, seperti reaksi mempertahankan tubuh melawan gravitasi, yang dapat membantu anak mempertahankan postur tegak lurus.

Anak-anak berkebutuhan khusus yang mengalami gangguan integrasi sensori seperti down syndrome, mempunyai ciri khas adanya tonus otot postural yang lemah, hal ini menyebabkan keterlambatan perkembangan motorik pada tahun pertama kehidupannya.Begitu juga dengan anak retardasi mental atau intelletual disability dan autism. Mereka juga mempunyai masalah dalam tonus otot yang lemah terutama tonus otot 
abdominal. Keterlambatan perkembangan pada anak dengan Down Syndrome (DS) disebabkan oleh low muscle tone, terutama pada kelompok otot yang dibutuhkan untuk memelihara posisi antigravitasi.Low muscle tone dan hypermobility yang muncul pada anakanak DS mempengaruhi perkembangan proximal stability dan automatic postural response. Sedangkan pada anak autism menunjukkan bahwa low muscle tone mempengaruhi postural reactiondan mobilitas anti gravitasi.Low muscle tonedan perkembangan postural control yang buruk berakibat proses input vestibular dan proprioseptif tidak sempurna (Blanceet al., 1998). Sehingga perlu dilakukan intervensi integrasisensori untuk memperbaiki kondisi low tonepada anak berkebutuhan khusus tersebut.

Dalam upaya membantu anak dengan tonus otot postural yang lemah ini, Okupasi terapis membantu mereka dengan aktivitas yang dapat meningkatkan tonus otot postural melalui pendekatan integrasi sensori. Al Hazmi (2013) menyatakan bahwa kombinasi neuro developmental treatment dan sensory integration lebih baik daripada hanya neuro developmental treatment untuk meningkatkan keseimbangan berdiri anak down syndrome. Hasil penelitian Parhoon \& Movallavi (2014) menyatakan bahwa stimulasi sensori dan edukasi dini anak dengan down syndrome dengan aktivitas motorik mampu membuat mereka mandiri dan mempunyai self-efficacy. Akan tetapi pada kenyataannya sampai sekarang para terapis di Indonesia masih belum memperhatikan kelemahan tonus postural pada anak berkebutuhan khusus dengan gangguan integrasi sensori sehingga hasil terapi yang selama ini dilakukan belum maksimal.
Hal inilah yang membuat peneliti tertarik untuk melakukan penelitian ini, dengan harapan akan memberikan manfaat untuk masyarakat luas terutama anak berkebutuhan khusus dan para terapis di Indonesia terutama di Surakarta.

\section{METODE PENELITIAN}

Penelitian ini didesain dengan rancangan quasi experimental dengan one group pretest-posttest design. Populasi penelitian ini adalah anak berkebutuhan khusus di Klinik Mitra Ananda Surakarta. Sampel dalam penelitian ini adalah anak berkebutuhan khusus dengan gangguan integrasi sensori di KlinikMitra Ananda Surakarta yang diketahui melalui pemeriksaan Short Sensory Profile. Pengambilan sampel dilakukan dengan teknik total sampling. Data penelitian berupa tonus otot anak diketahui berdasarkan skor pada instrumen pemeriksaan Clinical Observation of Neuromotor Performance.

\section{HASIL PENELITIAN}

\section{Tabel 1}

\section{Distribusi Frekuensi Sampel Penelitian Berdasarkan Jenis Kelamin}

\begin{tabular}{lll}
\hline Jenis Kelamin & Jumlah & \% \\
\hline Laki-laki & 5 & 41.67 \\
Perempuan & 7 & 58.33 \\
\hline Total & 12 & 100 \\
\hline \multicolumn{1}{c}{ Proporsi }
\end{tabular}

Proporsi responden penelitian ini didominasi responden berjenis kelamin perempuan. Populasi dalam penelitian ini adalah anak berkebutuhan khusus diKlinik Mitra Ananda Surakarta. Sampel penelitian ini adalah 12 responden yang mengikuti program penelitian secara rutin 1 minggu sekali selama 12 minggu dan 
melakukan semua aktivitas integrasi sensori dalam modul penelitian ini.

Berdasarkan klasifikasi profil sensorinya yang diketahui dari Short Sensory Profile pada saat pretest, disimpulkan bahwa semua responden (100 $\%)$ penelitian ini berada pada kondisi definite difference yang berarti mengalami gangguan integrasi sensori (Tabel 2).

Tabel 2

Distribusi Frekuensi Responden

Penelitian Berdasarkan Klasifikasi

Profil Sensorinya Menurut Short

Sensory Profile Pada Saat Pretest

\begin{tabular}{lll}
\hline Klasifikasi & Jumlah & $\mathbf{\%}$ \\
\hline Typical Performance & 0 & 0 \\
Probable Difference & 20 & 0 \\
Definite Difference & 12 & 100 \\
\hline Total & 12 & 100 \\
\hline
\end{tabular}

Tabel 3

Distribusi Frekuensi Skor Total Clinical Observation Of Neuromotor

Performance Sebelum Dan Sesudah Perlakuan

\begin{tabular}{ll}
\hline Waktu & Rerata Skor \\
\hline Pretest & 58.92 \\
Post test & 56.75 \\
Delta & 2.17 \\
\hline \multicolumn{1}{c}{ Berdasarkan } & nilai rerata skor
\end{tabular}

CONP sebelum dan sesudah perlakuan diketahui bahwa terdapat penurunan rerata skor CONP (2.17). Hal ini menunjukkan terdapat perbaikan tonus otot responden bila diukur dari performance neuromotor responden (Tabel 3).

Data penelitian dianalisis dengan paired sample t-test menggunakan program SPSS versi 17.0. Sebelum dilakukan uji hipotesis, dilakukan uji normalitas data dengan Shapiro-Wilk terhadap skor Clinical Observation of Neuromotor Performance sebelum dan sesudah perlakuan menunjukkan nilai $p$ - value> 0.05 yang berarti data normal. Kemudian dilakukan uji hipotesis dengan paired samplet-test. Hasil uji paired samplet-test pada tabel 4 menunjukkan tidak ada perbedaan yang signifikan $(p<0.05)$ tonus otot responden sebelum dan sesudah perlakuan berdasarkan skor Clinical Observation of Neuromotor Performanceresponden .

Tabel 4

Hasil Analisis Komparatif Skor Clinical Observation Of Neuromotor

Performance Sebelum Dan Sesudah Perlakuan

Paired Differences

\begin{tabular}{|c|c|c|c|c|}
\hline Pair 1 & \multicolumn{4}{|c|}{$95 \%$ Confidence Interval of the Difference } \\
\hline Lower & Upper & $\mathrm{t}$ & $\mathrm{df}$ & $\begin{array}{l}\text { Sig. (2- } \\
\text { tailed) }\end{array}$ \\
\hline-2.098 & 6.432 & 1.118 & 11 & .287 \\
\hline
\end{tabular}

\section{PEMBAHASAN}

Berdasarkan hasil uji hipotesis tersebut menunjukkan bahwa hasil penelitian ini berbeda dengan penelitian serupa yang dilakukan oleh Kurnianingsih, Saloko \& Sumaryanto (2016) di KTKA RSJD dr Soedjarwadi Klaten. Hal ini bias terjadi karena berbagai factor seperti perbedaan ketrampilan terapis, karakteristik sampel serta partisipasi sampel dalam penelitian ini. Menurut Bundy et al., (2002) dalam interpretasi teori Dunn tentang model integrasi sensori yang dapat diperiksa dengan pemeriksaan Clinical Observation of Neuromotor Performance diketahui bahwa pada komponen poor registration berhubungan dengan faktor endurancedan tonus otot yang rendah. Sensory processing berhubungan dengan endurance atau tone, dan modulasi gerakan mempengaruhi aktivitas individu. Dalam memproses informasi oleh Central 
Nervous System, input sensori visual, vestibular dan proprioseptif akan diekspresikan sebagai kemampuan individu dalam mempertahankan postur tubuh saat aktivitas yang dapat diukur dengan pemeriksaan Clinical Observation of Neuromotor Performance.

Prone extention merupakan kemampuan untuk memposisikan atau mempertahankan ekstensi trunk pada posisi tengkurap yang mengindikasikan kekuatan tonus postural ekstensi. Ayres menyatakan bahwa posisi ini merupakan indikasi yang kuat dalam fungsi vestibular dan proprioseptif. Bila seseorang kehilangan input vestibular dan proprioseptif pada otot ekstensor terutama pada area leher dan trunk, maka dia akan kehilangan kemampuan prone extention.

Prone extention dicek melalui demonstrasi kemampuan tersebut secara mandiri yang dapat dibantu dengan bantuan verbal atau fisik untuk memastikan klien memahami instruksi yang diharapkan dengan benar. Kualitas respon gerakan yang dilakukan dapat dilihat dari kemampuan : mendemonstrasikan posisi tengkurap dengan cepat (tidak secara segmental), mempertahankan kepala tegak 45 derajat posisi vertical, mengangkat bahu, dada, dan lengan di atas lantai, dan mampu bicara normal pada posisi tersebut tanpa menahan nafas. Anak usia 6 tahun seharusnya sudah mampu melakukan aktivitas tersebut dan bertahan minimal 30 detik (Bundy et al, 2002).

Neck flexion selama telentang memungkinkan input vestibular memfasilitasi head dan upper trunk tegak. Individu dengan poor vestibular processing kesulitan melakukan prone extention dan ada tendensi untuk mendongakkan kepala yang menyebabkan hilangnya input vestibular pada otot ekstensor leher. Proses vestibular ini juga mempengaruhi extensor muscle tone. Indikasi adanya low muscle tone dapat diketahui dengan adanya hyperextensibility distal joint, posisi berdiri lordosis dan hiperekstensi atau locked-knees, serta otot terasa lembek saat dipalpasi (Bundy et al, 2002).

Bundy et al, (2002) juga menyatakan bahwa stabilitas persendian mencerminkan kemampuan kontraksi tonic postural extensor muscle untuk menstabilisasi persendian di bagian atasnya selama weight bearing. Salah satu cara mengevaluasi proximal stability adalah dengan posisi quadruped sehingga dapat diamati adanya lordosis, hiperekstensi atau locked-elbow, naiknya posisi margo medialis scapulae, abduksi scapulae yang berlebihan

Schaaf et al., (2012) menyatakan bahwa aktivitas yang melibatkan active resisted sensory-motor seperti berayun pada trapeze, memanjat dinding, tengkurap (prone) pada net swing yang didorong sendiri dengan ekstremitas atas, merupakan aktivitas yang dapat memperbaiki poor sensory modulation and praxis. Sedangkan Delport et al., (2004) dalam critical review of the neuroscience and clinical literature related to prone extention dalam Ayres's Clinical Observation of Neuromotor Performance menyatakan bahwa menurut para ahli neuroscience, prone extention tergantung pada integrasi sistem vestibulo-proprioseptif yang cukup, mempunyai pengaruh yang berkebalikan dengan Tonic Labyrinthine Reflex dan Symmetrical Tonic Neck Reflex, serta membutuhkan inisiasi kortikal. Dalam aktivitas prone extention, otot-otot 
ekstensor distimulasi untuk menjaga kepala dan trunk tetap tegak.

Keterlambatan perkembangan pada anak dengan Down Syndrome (DS) disebabkan oleh low muscle tone, terutama pada kelompok otot yang dibutuhkan untuk memelihara posisi antigravitasi.Low muscle tone dan hypermobility yang muncul pada anakanak DS mempengaruhi perkembangan proximal stability dan automatic postural response. Sedangkan pada anak autism menunjukkan bahwa low muscle tone mempengaruhi postural reaction dan mobilitas anti gravitasi.Low muscle tone dan perkembangan postural control yang buruk berakibat proses input vestibular dan proprioseptif tidak sempurna (Blance et al., 1998).

Blance et al., (1998) juga menyatakan bahwa aktifitas wheelbarrow position yang merupakan salah satu aktivitas dalam penelitian ini mempunyai efek dalam integrasi neck proprioception, gravity reception dan ocular control serta memberikan input proprioseptif melalui ekstremitas atas. Efek dalam aspek motorik aktivitas wheelbarrow position adalah memelihara weight bearing dan weight shifting ekstremitas atas; memindahkan berat badan dengan aktif pada ekstremitas atas; memisahkan gerakan neck dari shoulder girdle serta mengaktifkan palmar archus melalui weight bearing dan weight shifting. Akan tetapi hasil penelitian ini menyatakan bahwa pengaruh ketrampilan integrasi sensori berbeda pada tiap individu atau sampel.

Perubahan tonus otot dapat dilihat dari perubahan rerata nilai pemeriksaan Clinical Observation of Neuromotor Performances. Setelah post test mengalami penurunan sebesar yaitu 2.17 yang walaupun kecil, telah menunjukkan sudah terjadi perubahan atau perbaikan tonus otot dari berbagai komponen dalam pemeriksaan tonus pada anak dengan gangguan integrasi sensori tersebut. Namun perbaikan tonus berdasarkan skor CONP ini belum memberikan dampak tonus otot yang signifikan.

\section{KESIMPULAN DAN SARAN}

Berdasarkan perbedaan skor CONP disimpulkan bahwa terapi integrasi sensori tidak memberikan pengaruh yang signifikan terhadap tonus otot pada anak dengan low tone di Klinik Mitra Ananda Surakarta. Diharapkan penelitian mendatang dapat memperbaiki bentuk intervensi yang dilakukan serta dapat diteliti pada sampel yang lebih banyak jumlahnya. Dalam upaya pengembangan penelitian serupa, diharapkan penelitian yang akan datang dapat menyempurnakan kelemahan penelitian ini dan menggunakan sampel penelitian yang lebih banyak serta mengembangan modul untuk meningkatkan hasil penelitian.

\section{DAFTAR RUJUKAN}

Ayres.A.J.,(1979). Sensory Integration and the child. Los Angeles: Wersternpsychological Services.

Bundy, A.C., Lane, S.J., \& Murray, E.A., (2002).Sensory integration theory and practice. $2^{\text {nd }}$ ed. Philadelphia: F.A. Davis Company.

Dunn.W.,\& Brown. N.B., (2010). Relationship between context and sensory processing in children with autism.The Am.J of OccTher.64(3).

Kurnianingsih, E.A ., Saloko, E., \& Sumaryanto, E., (2016). Pengaruh latihan integrasi sensori terhadap tonus anak dengan low tone di 
KTKA RSJD $\quad d r \quad$ Soedjarwadi Klaten.

Ed San Antonius : The Psychological corporation. Pp. 59-73

National Down Syndrome Society. (2015). Down syndrome.www.ndss.org

Parhoon. K., Parhoon. H.,\&Movallali. G., (2014).Effectiveness of training sensory stimulation on gross motor skills of 5-7 old children with down syndrome.

Schaaf, R.C., Hunt, J., \&Benevides, T.L. (2012). Occupational therapy using sensory to improve participant of a child with autism : A case report. Am Jour of OccTher. 66, 544555.http://dx.doi.org/10 5014/ajot 2012.004473
Schoeman, D., (2012). How can low muscle tone affect Johannesburg: Mind Moves Institute

Sue Delport. (2004). Sensor Net Newsletter (The Sensory Integration Network)Issue

Number 21.UK \& Ireland. Fathima Cassmijee Research Review.

The Children Indonesia. (2010). Down syndrome:Deteksi dini, pencegahan dan Penatalaksanaan sindrome down. KlinikAnak Online.Retrieved. 10 Agustus 2015

Tomchek. S.D.,\& Dunn. W. (2007). Sensory processing in children with and without autism. A comparative study using the short sensory profile. Am. Jour.Of OccTher.61(2). pp. 190-200. 